\title{
Liver-directed Gene Transfer and Prolonged Expression of Three Major Human ApoE Isoforms in ApoE-deficient Mice
}

\author{
Kazuhisa Tsukamoto, Pearle Smith, Jane M. Glick, and Daniel J. Rader \\ Department of Medicine and Department of Molecular and Cellular Engineering, University of Pennsylvania School of Medicine, \\ Philadelphia, Pennsylvania 19104
}

\begin{abstract}
Apolipoprotein E (apoE) plays a key role in lipoprotein metabolism and may have other important biological functions. In humans, there are three common, naturally occurring isoforms of apoE that are associated with differences in lipid levels and atherosclerosis. However, the direct in vivo effects of the apoE isoforms on lipoprotein metabolism and atherosclerosis are not yet fully understood. To investigate the effect of the apoE isoforms in vivo, we constructed second-generation recombinant adenoviruses encoding each of the apoE isoforms. These recombinant adenoviruses were injected intravenously into apoE-deficient mice fed a Western diet (mean baseline cholesterol level $1401 \mathrm{mg} / \mathrm{dl}$ ) in order to study their effects in the absence of endogenous mouse apoE. Hepatic expression of apoE3 and apoE4 completely normalized the lipoprotein profile; $3 \mathrm{~d}$ after injection, mean plasma cholesterol levels were 194 and $217 \mathrm{mg} /$ dl, respectively, and this effect was maintained for at least 6 wk. Expression of apoE2 had much less effect on lipoprotein levels (mean cholesterol level 752 mg/dl 3 d after injection), despite much higher plasma levels of apoE2 compared with apoE3 and apoE4; by 6 wk after injection the cholesterol levels had returned to baseline levels in the apoE2-expressing mice. Expression of all three isoforms significantly increased HDL cholesterol levels by approximately threefold and was independent of the cholesterol-lowering effect. ApoE transgene expression was substantially prolonged compared with that achieved using a first generation adenovirus and apoE was readily detected in plasma 3 mo after virus injection. These studies demonstrate: $(a)$ prolonged in vivo expression of human apoE isoforms in apoE deficient mice after second-generation recombinant adenovirus-mediated somatic gene transfer; and $(b)$ significantly impaired ability of apoE2 in vivo to mediate clearance of remnant lipoproteins in apoE-deficient mice fed a Western diet compared with apoE3 and apoE4. (J. Clin. Invest. 1997. 100:107114.) Key words: apoE isoform • gene transfer • adenoviral vector • lipoprotein metabolism • hyperlipoproteinemia
\end{abstract}

Address correspondence to Daniel J. Rader, M.D., University of Pennsylvania Medical Center, 409 Stellar Chance Labs, 422 Curie Blvd., Philadelphia, PA 19104. Phone: 215-898-4011; FAX: 215-5738606; E-mail: rader@mail.med.upenn.edu

Received for publication 26 December 1996 and accepted in revised form 2 April 1997.

J. Clin. Invest.

(C) The American Society for Clinical Investigation, Inc.

0021-9738/97/07/0107/08 \$2.00

Volume 100, Number 1, July 1997, 107-114

\section{Introduction}

Apolipoprotein E (apoE) is a 34-kD glycoprotein that plays a key role in lipoprotein metabolism (1). It mediates the uptake and degradation of chylomicron and VLDL remnants by acting as a ligand for the LDL receptor and the LDL receptorrelated protein (LRP) $(1,2)$. ApoE has also been proposed to have a variety of biological functions in addition to that in lipoprotein metabolism $(1,3,4)$. Genetic deficiency of apoE in humans $(5-8)$ and in mice $(9,10)$ results in a substantial increase in plasma levels of remnant lipoproteins. Certain rare mutations of apoE within the receptor binding region severely impair apoE binding and result in a dominant form of familial dysbetalipoproteinemia (Type III hyperlipoproteinemia) (11).

ApoE occurs in three major common isoforms in humans. ApoE3 (112 Cys, $158 \mathrm{Arg}$ ) is the most common isoform and is considered the wild type. ApoE4 (112 Arg, $158 \mathrm{Arg}$ ) and apoE2 (112 Cys, 158 Cys) differ from apoE3 by single amino acid substitutions. The North American allele frequency of apoE4 is $\sim 14 \%$ and of apoE2 is $\sim 7 \%$ (12). Both of these alternative apoE isoforms are clinically important. The presence of even one apoE4 allele is associated with slightly higher LDL cholesterol levels (12) and is also associated independently with an increased risk of coronary heart disease $(12,13)$. Homozygosity for apoE2 is associated with a recessive form of familial dysbetalipoproteinemia, although only a minority of apoE2/2 homozygotes actually develops hyperlipidemia (14). This phenomenon is not well understood but has been ascribed to the need for a second factor in addition to homozygosity for apoE2 for full expression of this lipid disorder (14).

The biological behavior of apoE2 and apoE4 relative to apoE3 has been studied using in vivo tracer studies in humans and in vitro binding studies in cell culture. Kinetic tracer studies in human subjects have established that the turnover of apoE2 is slower and apoE4 faster than that of apoE3 $(15,16)$. Although important in understanding the relative turnover of the apoE isoforms, these tracer studies do not directly address their impact on lipoprotein metabolism. Cell culture studies have demonstrated that apoE2 has little binding activity to the LDL receptor compared to apoE3 $(<2 \%)(1,17)$. This severe defect in binding in vitro is in contrast to the fact that most apoE2/2 homozygotes have normal lipid profiles. This discrepancy has never been fully resolved. Binding of apoE4 in culture is comparable to the binding of apoE3; the relative impact of apoE4 on lipoprotein metabolism compared to apoE3 has not been determined. Therefore there remain important questions regarding the relative effects of the three major apoE isoforms on lipoprotein metabolism in vivo.

To investigate the function of the apoE isoforms on lipoprotein metabolism without the confounding presence of endogenous apoE, we used somatic gene transfer of apoE isoforms in apoE-deficient mice. Recombinant adenoviruses have been used for somatic liver-directed gene transfer in several 
animal species (18). For example, two groups reported the use of a first-generation adenoviral vector for the transient expression of human apoE3 in apoE-deficient mice $(19,20)$. However, first-generation adenoviruses typically permit only shortterm expression of the transgene due to hepatic inflammation caused by the vector. Adenoviral protein expression in the liver from first-generation vectors results in a substantial immune response targeted toward the hepatocyte, leading to the loss of expression $(21,22)$. In contrast, a second-generation, temperature-sensitive, recombinant adenovirus has been reported to result in less immune response and substantially longer transgene expression in liver $(23,24)$. Therefore, we constructed recombinant second-generation adenoviruses encoding the human apoE2, apoE3, and apoE4 cDNAs. When injected into apoE-deficient mice fed a Western diet, these viruses resulted in high level, long-term expression of the appropriate apoE isoforms, allowing direct investigation of their in vivo effects on lipoprotein metabolism in the absence of endogenous apoE.

\section{Methods}

General methods. DNA and RNA manipulations were performed by standard techniques (25), and immunoblotting was also done by commonly used methods (26) unless otherwise indicated. The plasma total cholesterol and triglyceride levels were measured enzymatically on a Cobas Fara (Roche Diagnostic Systems Inc., Nutley, NJ) using Sigma reagents (Sigma Chemical Co., St. Louis, MO). The densitometric analysis was performed by using an imaging densitometer (Bio-Rad Laboratories, Hercules, CA) and Molecular Analyst software (Bio-Rad Laboratories).

Construction of recombinant adenoviruses. The plasmids used to create the replication-defective second-generation recombinant adenoviruses were constructed as follows. The human apoE3 cDNA was kindly provided by Dr. J. Smith and Dr. J. Breslow from The Rockefeller University (New York, NY). The plasmid was digested with $\mathrm{XbaI}$ to isolate human apoE3 cDNA. This fragment was subcloned into XbaI site of the pALTER-1 (Promega Corp., Madison, WI) and designated as pALTER-E3. By utilizing the altered sites II in vitro mutagenesis system kit (Promega Corp.), and using the oligonucleotides E2mut (5'-CTGCAGAAGTGCCTGGCAG-3') and E4mut (5'-GAGGACGTGCGCGGCCGCC-3'), mutagenesis of pALTERE3 was performed. After amplification of the relevant region of the apoE gene (from 398 to 664 bp of apoE cDNA) by PCR and digestion of the amplified PCR products with the restriction enzyme HhaI, which recognizes polymorphic sites of the apoE isoform cDNAs (27), we screened the mutagenized plasmids to confirm the appropriate mutagenesis. After the confirmation by PCR-RFLP, we performed sequencing of the clones by the dideoxy-chain termination method to confirm that there were no other mutations in the cDNA sequences. The mutated plasmids were designated as pALTER-E2 and pALTERE4, respectively.

These three plasmids, pALTER-E2, pALTER-E3, and pALTER$\mathrm{E} 4$, were digested with $\mathrm{XbaI}$, treated with Klenow enzyme, and human apoE2, apoE3, and apoE4 cDNAs were purified. These cDNAs were subcloned into the SnaBI site of the shuttle plasmid vector $\mathrm{pAd}$ CMV-link (24), which contains adenoviral 0-1 mU, the cytomegalovirus immediate early gene enhancer and promoter, and adenoviral 9-16 mU. After screening for the appropriate orientation by restriction analysis, the resulting plasmids were designated as pAdCMVE2, pAdCMVE3, and pAdCMVE4 respectively.

Recombinant adenoviruses were generated using established methods (28). The adenoviral DNA used for subsequent cotransfection was purified from H5.110CMVlacZ (lacZ virus) (24), which contains a temperature-sensitive mutation (ts125) in the E2A region of adenoviral DNA. This ts125 mutation renders the recombinant vi- ruses incapable of replication at $39^{\circ} \mathrm{C}(23)$. The three plasmids, pAdCMVE2, pAdCMVE3, and pAdCMVE4, were linearized with NheI and cotransfected into 293 cells along with adenoviral DNA digested with ClaI, and cells were overlaid with agar and incubated at $32^{\circ} \mathrm{C}$ for $15 \mathrm{~d}$. Plaques were picked and screened by PCR. Those positive for the apoE cDNA were further subjected to a second round of plaque purification after dilution. After confirmation of the presence of apoE cDNA and the absence of wild type adenovirus, the new recombinant adenoviruses were expanded in 293 cells. Cell lysates were used to infect HeLa cells for confirmation of the expression of human apoE by Western blotting of media. The recombinant adenoviruses, designated as H5.110CMVE2 (apoE2 virus), H5.110CMVE3 (apoE3 virus), and H5.110CMVE4 (apoE4 virus), were further expanded in 293 cells and purified by cesium chloride ultracentrifugation. Viral DNA was subjected to PCR-RFLP, and the genotypes were confirmed. The lacZ virus that carries $\beta$-galactosidase cDNA was also subjected to plaque purification and purified as mentioned above. All the recombinant viruses were confirmed to be incapable to grow at $39^{\circ} \mathrm{C}$. The purified viruses were stored in $10 \%$ glycerol $/ \mathrm{PBS}$ at $-80^{\circ} \mathrm{C}$.

Animal studies. Male apoE-deficient mice, 4-6 wk old, were obtained from Jackson Laboratory (Bar Harbor, ME). They were placed on a Western diet (normal chow supplemented with $0.15 \%$ cholesterol and $20 \%$ butter fat). 4 wk after initiation of the diet, they were injected intravenously with $1.5 \times 10^{11}$ particles $\left(4.5-6 \times 10^{9} \mathrm{pfu}\right)$ of apoE2, apoE3, apoE4, or lacZ viruses. Each group contained 7-8 mice. Blood was obtained from the retroorbital plexus after a 4-h fast before injection, $3 \mathrm{~d}$ after injection, and weekly over the course of the next 6 wk. Blood was collected into a tube containing EDTA, $\mathrm{NaN}_{3}$, gentamicin, PMSF, and benzamidine (the final concentrations are $2 \mathrm{mM}$, $0.2 \%, 0.77 \%, 1 \mathrm{mM}$, and $1 \mathrm{mM}$, respectively). Aliquots of plasma were stored at $4^{\circ}$ and $-20^{\circ} \mathrm{C}$. One animal from each group was killed on day 7 to analyze the mRNA expression in the liver (described below). A few mice from each group were maintained beyond the 6-wk experimental period to determine the duration of apoE expression.

Determination of apoE isoforms by isoelectric focusing (IEF). $5 \mu \mathrm{l}$ of plasma was delipidated using ethanol-ether as previously described (29). After delipidation, total protein was suspended in $100 \mu$ l of IEF ${ }^{1}$ sample buffer (100 mM Tris, $6 \mathrm{M}$ urea, $1 \% \mathrm{wt} / \mathrm{vol}$ sodium dodecyl sulfate, $5 \% \mathrm{vol} / \mathrm{vol}$ mercaptoethanol, $1 \%$ glycerol), and $20 \mu \mathrm{l}$ was loaded on an IEF gel ( $\mathrm{pH} 4-6.5)$. After electrophoresis, proteins were transferred to a nitrocellulose membrane (Schleicher \& Schuell, Keene, $\mathrm{NH}$ ), and human apoE isoforms were determined using a monoclonal antibody to human apoE (a kind gift from Dr. David Usher, University of Delaware) and peroxidase-labeled goat anti-mouse IgG antibody as a second antibody.

Detection and quantification of human apoE in mouse plasma. $2 \mu \mathrm{l}$ of mouse plasma were subjected to $10 \%$ SDS-PAGE. Proteins were transferred to nitrocellulose membrane, and human apoE was detected by a monoclonal antibody to human apoE and peroxidaselabeled goat anti-mouse IgG antibody. After the color development, the membranes were subjected to densitometric analysis. Plasma apoE levels were also measured using an immunoturbidometric assay (Wako Chemicals USA, Inc., Richmond, VA) on the Cobas Fara autoanalyzer.

Lipoprotein analysis. Pooled plasma samples $(120 \mu \mathrm{l})$ from 3 to 4 mice were subjected to fast protein liquid chromatography (FPLC) gel filtration (Pharmacia LKB Biotechnology, Uppsala, Sweden) on two Superose 6 columns as described (30). Each fraction was collected in $500 \mu \mathrm{l}$, and cholesterol concentrations were determined using an enzymatic assay kit (Wako Pure Chemical Industries, Ltd., Osaka, Japan). For estimation of the component of the plasma cholesterol present in each lipoprotein fraction, the percentages of cholesterol recovered from the column in the fractions forming the first peak, the

1. Abbreviations used in this paper: GAPDH, glyceraldehyde-3-phosphate dehydrogenase; IEF, isoelectric focusing. 
second peak, and the third peak were considered to be VLDL, intermediate density lipoprotein (IDL)/LDL, and HDL, respectively.

Distribution of human apoE in lipoprotein classes. After separating the pooled plasma samples on FPLC, $50-\mu 1$ samples from two adjacent fractions were pooled and subjected to $10 \%$ SDS-PAGE. Human apoE was detected by Western blotting as described above. After color development, the membranes were subjected to densitometric analysis.

Northern blotting analysis of human apoE $m R N A$ in liver. One mouse from each group was killed $7 \mathrm{~d}$ after the injection of virus, and a liver sample was quickly frozen in liquid nitrogen and stored at $-80^{\circ} \mathrm{C}$. The sample was homogenized in TRIzol Reagent (GIBCOBRL, Grand Island, NY), and total RNA was purified and dissolved in FORMAzol (Molecular Research Center, Inc., Cincinnati, OH). 25 $\mu \mathrm{g}$ of total RNA was loaded on a formaldehyde-agarose gel, blotted to Hybond-N+ (Amersham Life Science, Amersham, UK), and hybridized with apoE3 cDNA labeled with digoxigenin utilizing the Genius DNA labeling kit (Boehringer Mannheim Corp., Indianapolis, IN). After the incubation with anti-digoxigenin antibody conjugated with alkaline phosphatase, color was developed using nitroblue tetrazolium and 5-bromo-4-chloro-3-indolyl phosphate, followed by densitometric analysis. The apoE probe was then stripped, and the membrane was reprobed with mouse glyceraldehyde-3-phosphate dehydrogenase (GAPDH) cDNA labeled with digoxigenin.

\section{Results}

The DNA of apoE isoform recombinant adenoviruses was subjected to PCR-RFLP and the apoE genotypes were confirmed (Fig. 1). To confirm the expression of the appropriate apoE isoform in vivo, the mouse plasma samples obtained $7 \mathrm{~d}$ after injection were subjected to IEF followed by Western blotting. Fig. 2 demonstrates in vivo expression of the expected apoE isoforms.

Plasma concentrations of human apoE were determined using an immunoturbidometric assay (Table I). There were substantial differences in the plasma concentrations of apoE among the three isoforms. On day 3 postinjection, the concentration of apoE2 was 5-fold higher than that of apoE3, which in turn was 1.5-fold higher than that of apoE4. On day 7, the level of apoE2 was 9-fold greater than that of apoE3, which was 1.6-fold greater than that of apoE4. Fig. $3 \mathrm{D}$ shows representative Western blots of plasma human apoE on days 3 and 7 in mice injected with the three apoE adenoviruses.

To determine the duration of expression of apoE proteins, Western blotting of human apoE after separation by SDS-

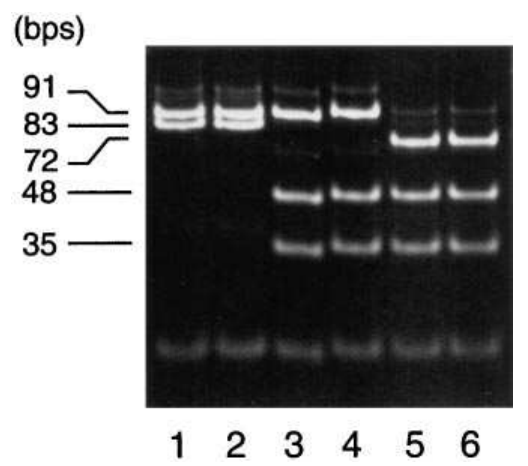

Figure 1. Genotyping of the three apoE isoform adenoviruses. After amplification of the relevant region of the apoE gene by PCR, the PCR products were digested with the restriction enzyme HhaI and subjected to $20 \%$ polyacrylamide gel electrophoresis. The template DNA used for amplification are as follows:

lane 1, plasmid pAdCMVE2; lane 2, apoE2 virus; lane 3, plasmid pAdCMVE3; lane 4, apoE3 virus; lane 5, plasmid pAdCMVE4; lane 6 , apoE4 virus.

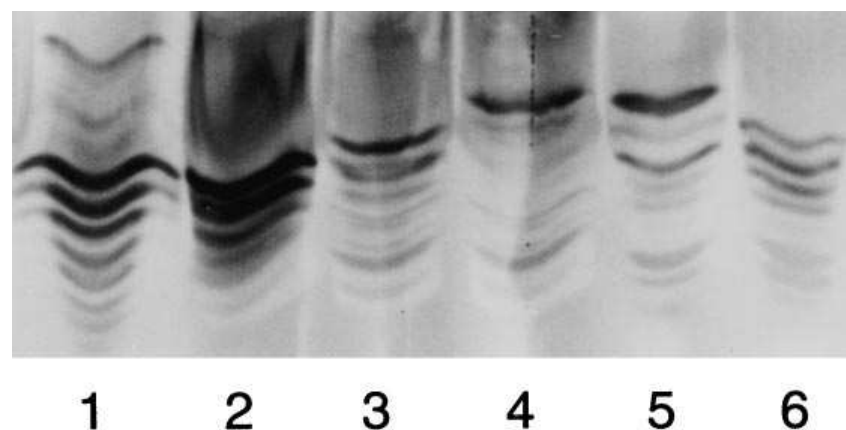

Figure 2. Phenotyping of the three apoE isoforms expressed in vivo after gene transfer. After delipidation of $10 \mu l$ of plasma, samples were dissolved in IEF buffer, and 1/5 vol of each sample was loaded on an IEF gel ( $\mathrm{pH} 4.5-6)$. After electrophoresis, the proteins were transferred to a nitrocellulose membrane, and apoE protein was detected with monoclonal antibody raised against human apoE. (Lane 1) Human apoE2/E2 plasma sample; (lane 2) plasma sample from a mouse injected with apoE2 virus; (lane 3) plasma sample from a mouse injected with apoE3 virus; (lane 4) plasma sample from a mouse injected with apoE4 virus; (lane 5) human apoE4/E4 plasma sample; (lane 6) human apoE3/E3 plasma sample.

PAGE was performed on plasma obtained at multiple time points after injection of viruses (Fig. 3). Fig. 3, $A, B$, and $C$ show the time courses of apoE in the plasma of mice injected with the apoE2, apoE3, and apoE4 viruses, respectively. The plasma concentration of apoE declined fairly rapidly from day 7 to day 14, followed by gradual decline. In all groups, apoE protein was still expressed 3 mo after injection of the adenoviruses. The plasma apoE levels on day 84 were approximately one fourth of normal human levels for apoE3 and apoE4 and were higher than normal human levels for apoE2.

To determine whether the observed differences in plasma apoE concentrations were a reflection of differential apoE gene expression, hepatic apoE mRNA levels were evaluated

Table I. Plasma ApoE Levels in the Animals Injected with ApoE Isoform Viruses

\begin{tabular}{ccccc}
\hline & \multicolumn{4}{c}{ Adenovirus } \\
\cline { 2 - 5 } Day & LacZ & E2 & E3 & E4 \\
\hline \multirow{4}{*}{3} & & $\mu g / m l$ & \\
& & 1560 & 312 & 219 \\
7 & $(230)$ & $(196)$ & $(286)$ \\
& & 609 & 68 & 43 \\
14 & 0 & $(248)$ & $(31)$ & $(36)$ \\
& & 163 & 26 & 15 \\
21 & ND & $(54)$ & $(14)$ & $(3.8)$ \\
& & 170 & 15 & 12 \\
28 & ND & $(54)$ & $(2.6)$ & $(3.0)$ \\
& & 162 & 13 & 10 \\
42 & ND & $(54)$ & $(3.0)$ & $(2.2)$ \\
& & 129 & 9.8 & 8.4 \\
& ND & $(49)$ & $(2.8)$ & $(3.0)$ \\
\hline
\end{tabular}

Plasma apoE concentration was measured using an immunoturbidometric assay. The values are mean (SD). ND, not determined. 
A

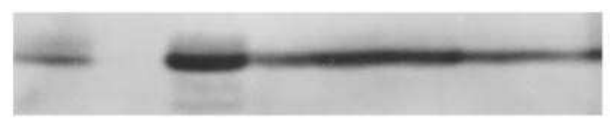

B

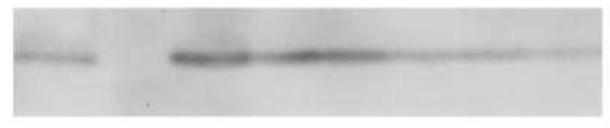

C

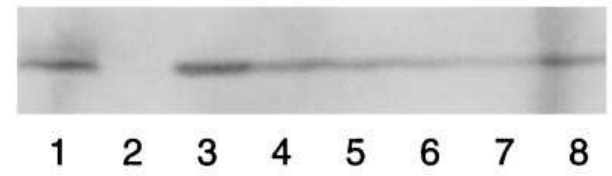

D

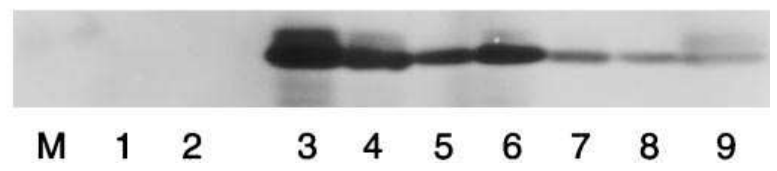

Figure 3. Western blotting analysis of the plasma samples of the mice injected with recombinant apoE adenoviruses. After separating $2 \mu \mathrm{l}$ of plasma sample by SDS-PAGE, proteins were transferred to a nitrocellulose membrane, and apoE was detected with a monoclonal antibody against human apoE. $(A, B$, and $C)$ The time course changes in plasma concentration of the apoE proteins in representative mice. $(A)$ samples from a mouse injected with apoE2 virus, $(B)$ samples from a mouse injected with apoE3 virus, and $(C)$ samples from a mouse injected with apoE4 virus. (Lane 1) Control human plasma; (lane 2) mouse plasma drawn before injection of the virus; (lane 3) day 7; (lane 4) day 14; (lane 5) day 28; (lane 6) day 42; (lane 7) day 63 (lane 8 ) day 84. (D) Mouse plasma samples on day 3 and 7 and analyzed by Western blotting. (Lane $M$ ) Molecular weight markers; (lanes 1 and 2) plasma samples from mouse injected with control (lacZ) adenovirus on day 3 and 7, respectively; (lanes 3-5) plasma samples on day 3 from mice injected with apoE2, and apoE3, and apoE4 viruses, respectively; (Lanes 6-8) plasma samples on day 7 from mice injected with apoE2, and apoE3, and apoE4, respectively; (Lane 9) control human plasma sample.

by Northern blotting utilizing mouse GAPDH mRNA as an internal control (Fig. 4). Because more than $90 \%$ of recombinant adenovirus infused intravenously is known to be delivered to the liver (31), liver samples were subjected to analysis. The relative ratios of apoE mRNA to GAPDH mRNA were $1.34,1.10$, and 1.00 for apoE2, apoE3, and apoE4, respectively. Thus, the differences in plasma concentrations of apoE among the isoforms were not due to differences in mRNA abundance.

We observed significantly different effects of the three apoE isoforms on plasma cholesterol and lipoproteins in these mice fed a Western diet. As shown in Fig. 5, plasma total cholesterol levels in mice injected with the apoE3 virus decreased dramatically after injection. The mean cholesterol level was $1,384 \mathrm{mg} / \mathrm{dl}$ before injection, falling to $194 \mathrm{mg} / \mathrm{dl} 3 \mathrm{~d}$ after injection. This marked decrease in cholesterol levels was sustained throughout the $42 \mathrm{~d}$ of the study, although cholesterol levels began to gradually increase after day 28 . Mice injected with the apoE4 virus revealed virtually the same pattern as that of mice injected with apoE3 virus (mean cholesterol 1,345 mg/dl before injection and $217 \mathrm{mg} / \mathrm{dl} 3 \mathrm{~d}$ after injection). The cholesterol level in this group began increasing gradually after day 21 , but still remained much lower than the baseline level by day 42. The mice injected with the apoE2 virus showed a very different response compared with mice injected with the
A

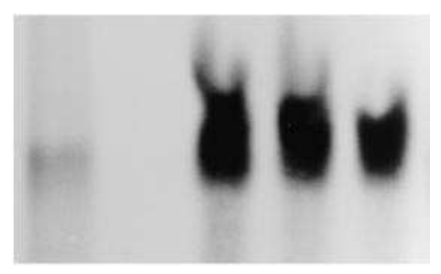

B

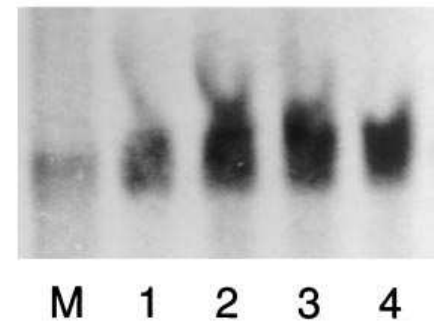

Figure 4. Northern blotting analysis of mRNA from liver. 25 $\mu \mathrm{g}$ of total RNA purified from the livers of mice killed $7 \mathrm{~d}$ after inseparated on a gel and apoE cDNA or $(B)$ mouse GAPDH cDNA. (Lane 1) RNA molecular weight markers, the band represents $1.3 \mathrm{~kb}$; (lane 2) mouse injected with lacZ virus; (lane 3 ) mouse injected with apoE2 virus; (lane 4) mouse injected with apoE3 virus; and (lane 5) mouse injected with apoE4 virus. jection of viruses was probed with $(A)$ human

apoE3 or apoE4 viruses. The effect on total cholesterol was slower and much less substantial; the maximum decrease in plasma total cholesterol level occurred $14 \mathrm{~d}$ after injection, with the mean level falling to $452 \mathrm{mg} / \mathrm{dl}$ from a preinjection mean level of $1,474 \mathrm{mg} / \mathrm{dl}$. Cholesterol levels in the apoE2injected mice returned to baseline levels by day 42 .

To determine the effects of the various apoE isoforms on individual lipoprotein classes, FPLC gel filtration of pooled plasma samples was performed (Fig. 6). There was no differ-

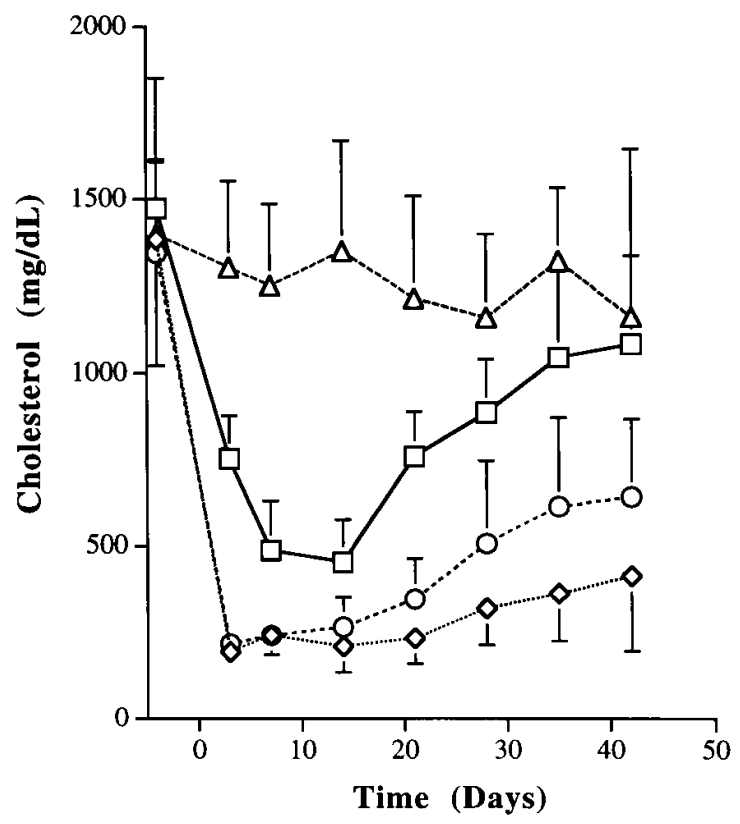

Figure 5. Changes in plasma total cholesterol. Plasma total cholesterol levels were measured enzymatically as described in Methods. (squares) Mice injected with apoE2 virus $(n=7)$; (diamonds) mice injected with apoE3 virus $(n=6)$; (circles) mice injected with apoE4 virus $(n=7)$; and (triangles) mice injected with control lac $Z$ virus $(n=6)$. Data are mean \pm SD. 

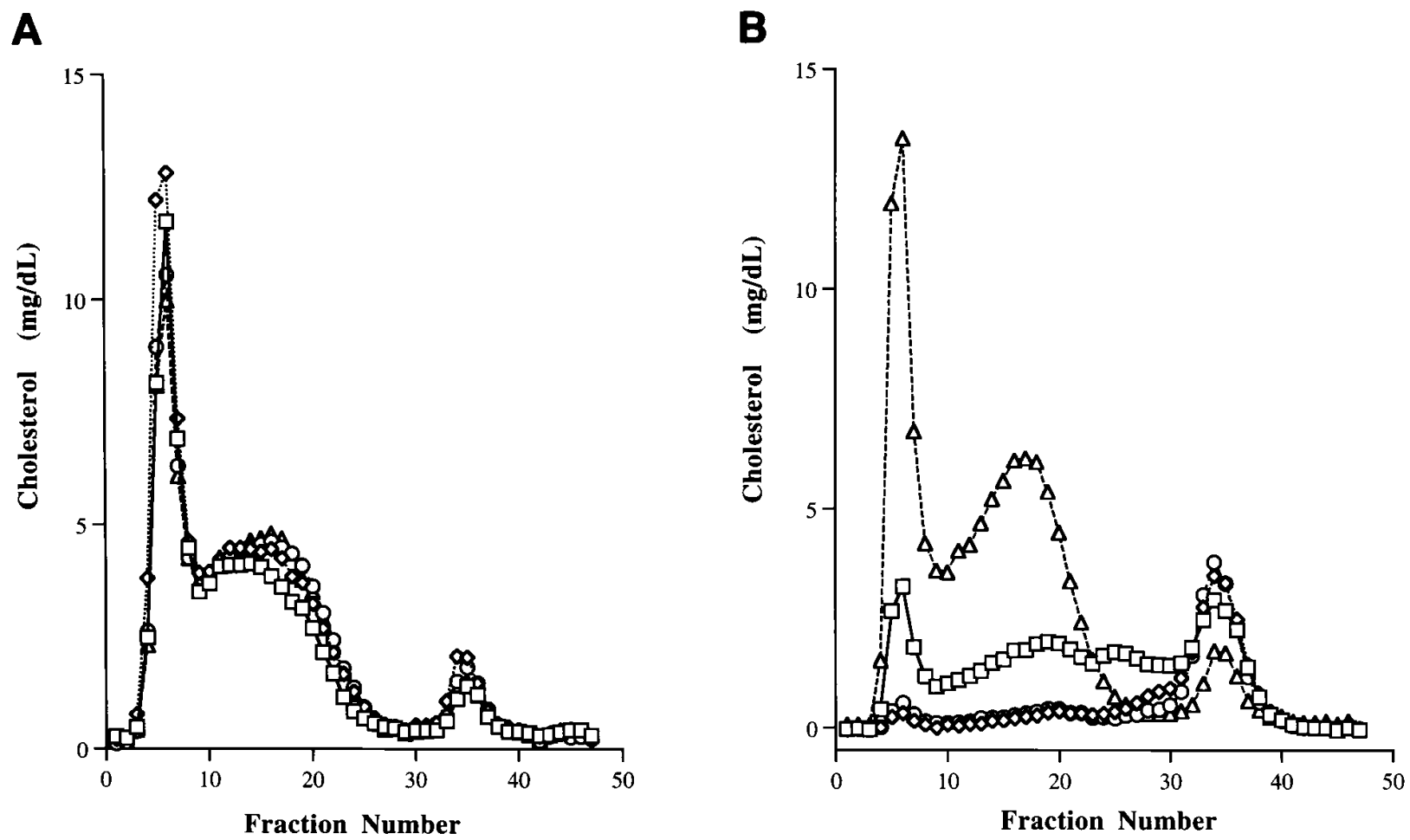

Figure 6. FPLC cholesterol profile. Pooled plasma samples were subjected to gel filtration using Superose 6 columns, and the cholesterol level in each fraction was measured by using an enzymatic assay kit. $(A)$ Data from samples collected before injection of viruses, and $(B)$ data from samples collected $7 \mathrm{~d}$ after injection of viruses. (squares) Mice injected with apoE2 virus; (diamonds) mice injected with apoE3 virus; (circles) mice injected with apoE4 virus; and (triangles) mice injected with control lacZ virus.

ence between groups in the FPLC cholesterol profile before injection of the viruses. $7 \mathrm{~d}$ after injection, the VLDL and IDL/ LDL cholesterol levels normalized in mice injected with apoE3 or apoE4 viruses, and HDL cholesterol increased. Analysis of plasma from mice injected with the apoE2 virus revealed a much smaller decrease in VLDL and IDL/LDL cholesterol levels and an appearance of lipoproteins between the normal LDL and HDL size ranges. The HDL cholesterol level in this group increased to almost the same level as in apoE3 and apoE4 virus-injected mice.

The VLDL cholesterol (VLDL-C), IDL and LDL cholesterol (IDL/LDL-C), and HDL cholesterol (HDL-C) levels were determined from the FPLC fractions over the 6-wk course of the experiment and are shown in Fig 7. The VLDL-C levels
A

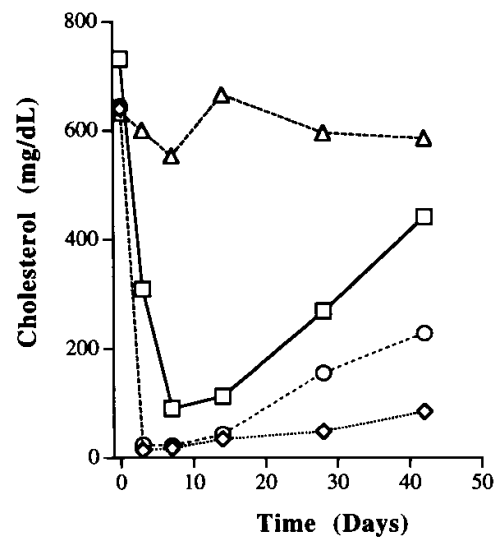

B

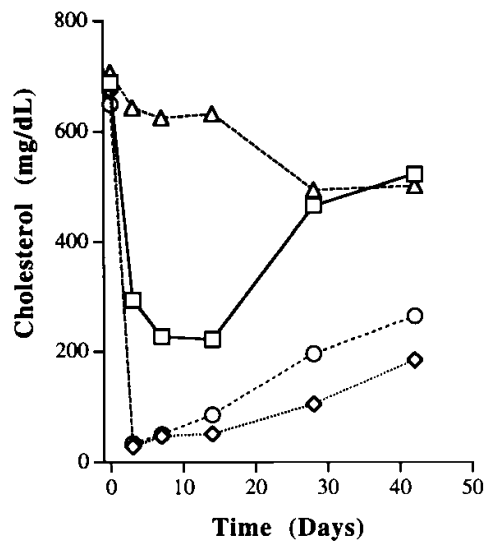

C

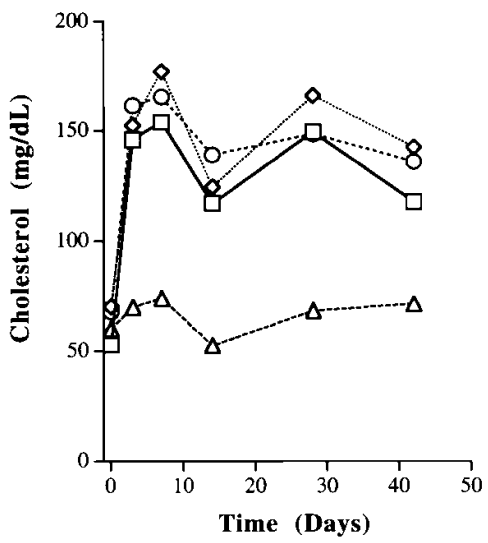

Figure 7. Cholesterol changes in lipoprotein subclasses. Pooled plasma samples were subjected to gel filtration using Superose 6 columns, followed by cholesterol measurement in each fraction. After calculating the percentage of cholesterol recovered in the VLDL, IDL/LDL, and HDL fractions, the actual VLDL-C, IDL/LDL-C, and HDL-C levels in plasma were calculated by multiplying each by the plasma cholesterol level. $(A)$ VLDL cholesterol, (B) IDL/LDL cholesterol, and (C) HDL cholesterol. (squares) Mice injected with apoE2 virus; (diamonds) mice injected with apoE3 virus; (circles) mice injected with apoE4 virus; and (triangles) mice injected with control lacZ virus. 


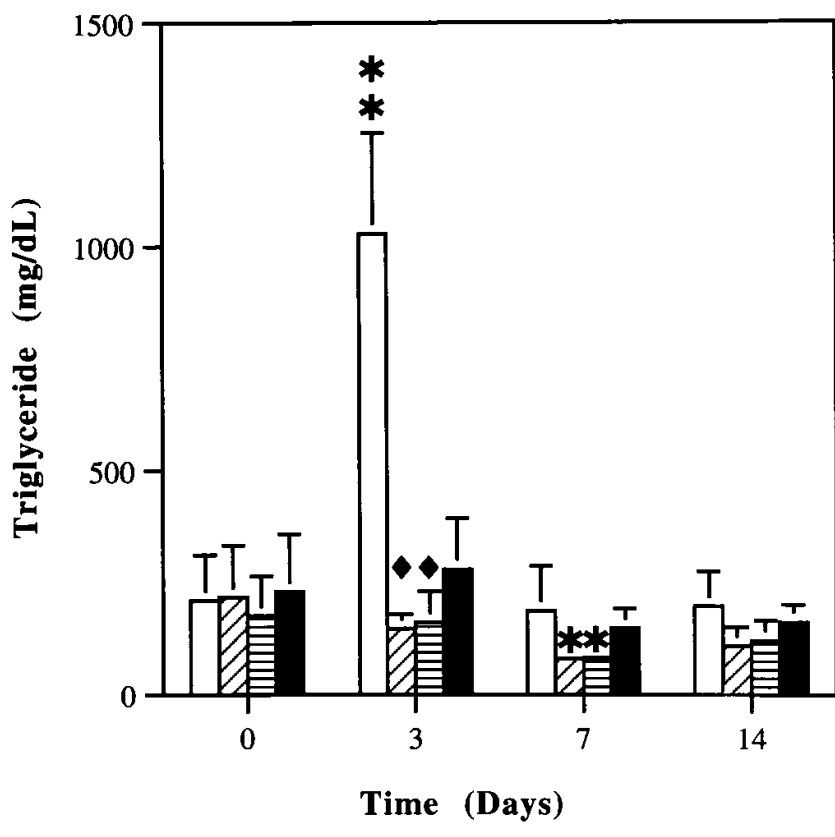

Figure 8. Changes in plasma triglycerides. Plasma triglyceride levels were measured enzymatically as described. Open bars represent mice injected with apoE2 virus $(n=7)$, bars with slanted lines mice injected with apoE3 virus $(n=6)$, bars with horizontal lines mice injected with apoE4 virus $(n=7)$, and closed bars mice injected with control lacZ virus $(n=6)$. Data are mean \pm SD. $(* *) P<0.0001 \mathrm{com}-$ pared with all other groups on the same day; (*) $P<0.01$ compared with control, and (closed diamond) $P<0.04$ compared with control at the same time point.

and IDL/LDL-C levels decreased dramatically in mice injected with apoE3 and apoE4 viruses, whereas the mice injected with apoE2 virus had a more moderate decrease. In addition, after day 28 , the IDL/LDL-C level in mice injected with apoE2 virus rose to the same level as the mice injected with control virus. The changes in HDL-C level (Fig. 7 C) were similar among the mice injected with apoE2, apoE3, and apoE4 viruses, showing increases in HDL-C level of approximately threefold, which were sustained through day 42 .

The changes in plasma triglyceride (TG) level are shown in Fig. 8. There was no change in the TG level of the mice injected with control virus. Mice injected with the apoE2 virus had a significant increase in TG level $3 \mathrm{~d}$ after injection of the virus. However, by $7 \mathrm{~d}$ after injection, TG in these mice had returned to the baseline level. In contrast, mice injected with the apoE3 and apoE4 viruses had small but significant decreases in plasma TG levels.

To examine whether there was a difference in the pattern of distribution of these three apoE isoforms among lipoprotein classes, aliquots of the fractionated samples from FPLC gel filtration were subjected to SDS-PAGE and analyzed by Western blotting. Fig. 9 shows the results from the samples drawn on day 7. All apoE isoforms distributed on all lipoprotein classes, however, there was a difference in their patterns of distribution. To approximate the amount of apoE per lipoprotein particle, the apoE protein concentration in each lipoprotein fraction was divided by the cholesterol concentration in each fraction. As shown in Table II, the ratio of apoE2/cholesterol
Table II. Ratio of ApoE/Cholesterol in Each Lipoprotein Subclass on Day 7 Postinjection

\begin{tabular}{lccr}
\hline & \multicolumn{3}{c}{ Lipoprotein subclass } \\
\cline { 2 - 4 } Adenovirus & VLDL & IDL/LDL & HDL \\
\hline & & $\mu g$ apoE/mg cholesterol \\
apoE2 & 95 & 144 & \\
apoE3 & 17 & 63 & 125 \\
apoE4 & 24 & 46 & 9
\end{tabular}

was much higher in all lipoprotein classes than that of apoE3 or apoE4, indicating a much greater amount of apoE2 per particle. These ratios also indicate that apoE4 distributed preferentially to VLDL and apoE2 to HDL as compared with apoE3.

\section{Discussion}

Few data exist comparing the direct effects of the three major apoE isoforms on lipoprotein metabolism in vivo. The purpose of this study was to investigate the influence of the three human apoE isoforms on lipoprotein metabolism in the absence of endogenous apoE by utilizing liver-directed somatic gene transfer in apoE-deficient mice. Replication-defective recombinant adenoviruses have been utilized for the study of effects of gene expression in vivo, and have been especially useful in the investigation of effects on lipoprotein metabolism (32). However, one drawback has been the short duration of gene expression and high degree of inflammation using first-generation adenoviruses (28). We previously used a first-generation recombinant adenovirus encoding the human apoE3 cDNA in mice, but the expression of apoE was extremely low by day 28 (data not shown), consistent with other reports $(19,20)$. Second-generation temperature-sensitive recombinant adenoviruses were reported to result in less inflammation and longer expression of $\beta$-galactosidase (23) and ornithine transcarbamylase (24) in mouse liver compared to first-generation adenoviruses. This study is the first report of the use of a second-generation adenovirus for gene transfer and expression of a secreted protein. The advantage of a secreted protein is that it can be repetitively measured in the same animals over time, allowing a more quantitative assessment of the duration of transgene expression and the biological effects of expression over time. These studies revealed that not only was the level of apoE expression high, but it was maintained for a much longer period of time than with first-generation adenoviral vectors. ApoE was present at levels comparable to or greater than normal human levels for at least 3 mo after injection of adenovirus.

The injection of the same doses of recombinant adenoviruses encoding each of the three apoE isoforms resulted in approximately the same level of expression of the transgene based on the level of mRNA abundance in the liver as measured $7 \mathrm{~d}$ after injection. However, the plasma concentrations of apoE2 were markedly greater than that of apoE3 or apoE4, and levels of apoE3 were greater than those of apoE4. ApoE2 levels remained substantially higher than apoE3 and apoE4 throughout the study even up to 3 mo after injection. These data are consistent with previous tracer turnover studies suggesting that in humans the turnover of apoE2 is slowest and apoE4 is fastest among these three isoforms $(15,16)$. 
A

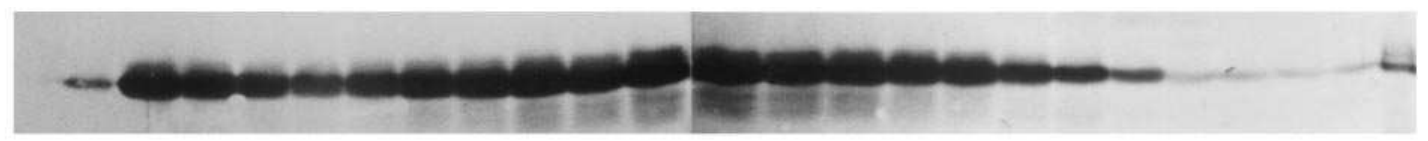

B

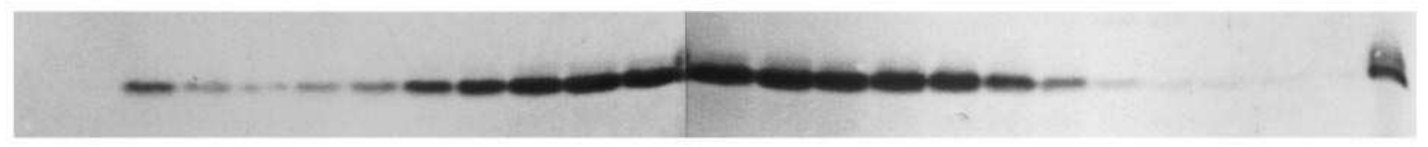

C

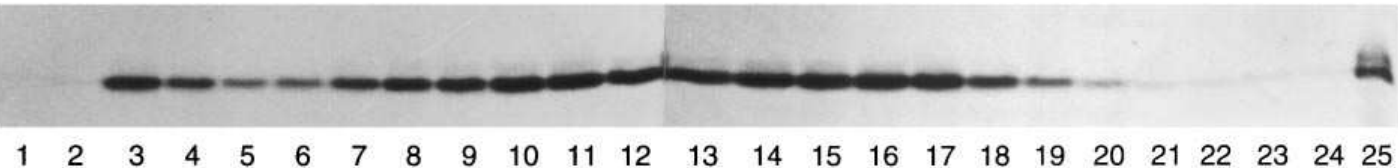

Figure 9. Distribution of apolipoprotein E among lipoprotein classes. 50- $\mu \mathrm{l}$ samples from two adjacent FPLC fractions were pooled and subjected to SDS-PAGE, followed by Western blotting analysis with a monoclonal antibody against human apoE. $(A)$ Samples from mice injected with apoE2 virus, $(B)$ samples from mice injected with apoE3 virus, $(C)$ samples from mice injected with apoE4 virus. (Lanes 2-5) VLDL fractions, (lanes 6-13) IDL/LDL fractions, (lanes 14-20) HDL fractions, and (lanes 21-24) lipoprotein "free" fractions. Lane 25 is $2 \mu 1$ of a human control plasma sample.

Hepatic gene transfer of apoE3 and apoE4 in apoE-deficient mice fed a Western diet completely normalized plasma cholesterol levels by reducing VLDL and IDL/LDL. In contrast, gene transfer of apoE2 was not nearly as effective in reducing cholesterol and lipoprotein levels. Furthermore, the nadir did not occur until $14 \mathrm{~d}$ after injection of the apoE2 virus. Therefore, although apoE2 did have some effect on lipoprotein metabolism in this model, the effect was markedly attenuated compared with that of apoE3 and apoE4.

The acute effect of apoE gene transfer on triglyceride levels did not always directly correlate with changes in cholesterol levels. Mice injected with the apoE2 virus had an acute increase in triglyceride levels on day 3 despite a modest decrease in cholesterol levels. In contrast, mice injected with the apoE3 and apoE4 viruses had a modest decrease in triglyceride levels. Several in vitro studies demonstrated that apoE inhibited lipolysis at high concentration $(33,34)$. At high levels, apoE may also have an acute inhibitory effect on lipolysis of TG-rich lipoproteins in vivo. Testing of this hypothesis will require further investigation.

Despite differences in the effect of apoE isoforms on apoBcontaining lipoproteins, gene transfer of all three apoE isoforms produced a sustained increase in HDL cholesterol levels of approximately threefold compared to the baseline level, which was maintained throughout the course of the experiment. This increase in HDL levels may be in part associated with the decrease in VLDL and IDL/LDL. However, in mice injected with the apoE2 virus, whose VLDL and IDL/LDL levels on day 42 had returned back to control levels, a similar sustained increase in HDL was observed. Therefore, apoE itself may have contributed to increased HDL cholesterol by enhancing the formation of apoE-rich HDL particles. The observation that all apoE isoforms were found in abundance in the HDL fraction is consistent with this interpretation.

The distribution of apoE isoforms in vivo was similar to that predicted by tracer studies. A greater fraction of apoE2 associated with HDL and a higher fraction of apoE4 associated with VLDL relative to apoE3. It is of interest that the human apoE isoforms are consistent in their predilection for specific lipoprotein particles even in mice.
We observed increases in plasma cholesterol levels and remnant lipoproteins over time that were different for the three isoforms. In mice injected with the apoE2 virus, cholesterol levels rebounded rapidly to the baseline level; in mice injected with the apoE4 virus, cholesterol levels started increasing at day 21; and in mice injected with the apoE3 virus cholesterol levels began to increase gradually at day 28 . It is likely that there is a threshold plasma concentration of human apoE3 and apoE4 required to normalize the plasma cholesterol level in apoE-deficient mice on a Western diet. Plasma levels of apoE4 on days 14 and 21 were $15.0 \mu \mathrm{g} / \mathrm{ml}$ and $11.6 \mu \mathrm{g} /$ $\mathrm{ml}$, respectively, and those of apoE3 on days 21 and 28 were $15.4 \mu \mathrm{g} / \mathrm{ml}$ and $13.3 \mu \mathrm{g} / \mathrm{ml}$, respectively. Therefore, approximately one third of the normal human apoE plasma concentration is necessary for apoE3 and apoE4 to normalize cholesterol levels in these mice when fed a Western diet. In contrast, a previous report (35) demonstrated that one tenth of the normal apoE plasma concentration in apoE-deficient mice fed normal chow was sufficient to normalize the lipoprotein profile.

Another possible explanation for the increase in cholesterol levels is the generation of antibodies to human apoE. Previous studies (36-38) utilizing recombinant adenoviruses as a vehicle for gene transfer report production of antibodies to the transgene $3 \mathrm{wk}$ after the injection. Human apoE is a neoantigen to apoE-deficient mice, making it likely that antibody against apoE would be produced. Over the time course of this experiment, we detected only a very small titer of antibody to human apoE that was first detectable on day 28 . There was no apparent difference among the three isoforms. Therefore, an immune response to the apoE is unlikely to be a major factor in influencing these results.

In summary, second-generation recombinant adenoviruses were used to achieve high level, long-term hepatic gene expression of all three major human apoE isoforms in apoE-deficient mice fed a Western diet. On this background of absent endogenous apoE, their differential effects on lipoprotein metabolism were determined. The use of second generation adenoviruses for somatic gene transfer of apoE should permit further investigation of apoE isoform effects on longer term endpoints such as atherosclerosis. 


\section{Acknowledgments}

We are indebted to Kevin G. Hiester for excellent technical assistance, to Dr. Karen Kozarsky for helpful discussions, to Dr. James Wilson for providing the second generation lacZ adenovirus, and to Dr. David Usher for antibodies to human apoE.

This research was supported in part by grants to D.J. Rader from the W.W. Smith Charitable Trust, the National Institutes of Health (HL55323), the American Heart Association and the American Health Assistance Foundation.

\section{References}

1. Mahley, R.W. 1988. Apolipoprotein E: cholesterol transport protein with expanding role in cell biology. Science (Wash. DC). 240:622-630.

2. Beisiegel, U. 1995. Receptors for triglyceride-rich lipoproteins and their role in lipoprotein metabolism. (Review.) Curr. Opin. Lipidol. 6:117-122.

3. Nathan, B.P., S. Bellosta, D.A. Sanan, K.H. Weisgraber, R.W. Mahley, and R.E. Pitas. 1994. Differential effects of apolipoproteins E3 and E4 on neuronal growth in vitro. Science (Wash. DC). 264:850-852.

4. Strittmatter, W.J., and A.D. Roses. 1995. Apolipoprotein E and Alzheimer disease (Review.) Proc. Natl. Acad. Sci. USA. 92:4725-4727.

5. Ghiselli, G., E.J. Schaefer, P. Gascon, and H.B. Breser, Jr. 1981. Type III hyperlipoproteinemia associated with apolipoprotein E deficiency. Science (Wash. DC). 214:1239-1241.

6. Mabuchi, H., H. Itoh, M. Takeda, K. Kajinami, T. Wakasugi, J. Koizumi, R. Takeda, and C. Asagami. 1989. A young type III hyperlipoproteinemic patient associated with apolipoproteinemic patient associated with apolipoprotein E deficiency. Metab. Clin. Exp. 38:115-119.

7. Kurosaka, D., T. Teramoto, T. Matsushima, T. Yokoyama, A. Yamanda, T. Aikawa, Y. Miyamoto, and K. Kurokawa. 1991. Apolipoprotein E deficiency with a depressed mRNA of normal size. Atherosclerosis. 88:15-20.

8. Feussner, G., J. Dobmeyer, H.J. Grone, S. Lohmer, and S. Wohlfeil. 1996. A 10-bp deletion in the apolipoprotein epsilon gene causing apolipoprotein E deficiency and severe type III hyperlipoproteinemia. Am. J. Hum. Genet. 58:281-291.

9. Plump, A.S., J.D. Smith, T. Hayek, K. Aalto-Setälä, A. Walsh, J.G. Verstuyft, E.M. Rubin, and J.L. Breslow. 1992. Severe hypercholesterolemia and atherosclerosis in apolipoprotein E-deficient mice created by homologous recombination in ES cells. Cell. 71:343-353.

10. Zhang, S., R. Reddick, J. Piedrahita, and N. Maeda. 1992. Spontaneous hypercholesterolemia and arterial lesions in mice lacking apolipoprotein E. Science (Wash. DC). 258:468-471.

11. Rall, S.C., Jr., and R.W. Mahley. 1992. The role of apolipopreotein E genetic variants in lipoprotein disorders. (Review.) J. Intern. Med. 231:653-659.

12. Davignon, J., R.E. Gregg, and C.F. Sing. 1988. Apolipoprotein E polymorphism and atherosclerosis. Arteriosclerosis. 8:1-21.

13. Wilson, P.W.F., R.H. Myers, M.G. Larson, J.M. Ordovas, P.A. Wolf, and E.J. Schaefer. 1994. Apolipoprotein E Alleles, Dyslipidemia, and coronary heart disease. JAMA. 272:1666-1671.

14. Brewer, H.B., Jr., L.A. Zech, R.E. Gregg, D. Schwartz, and E.J. Schaefer. 1983. Type III hyperlipoproteinemia: diagnosis, molecular defects, pathology, and treatment. Ann. Intern. Med. 98:623-640.

15. Gregg, R.E., L.A. Zech, E.J. Schaefer, and H.B. Brewer, Jr. 1981. Type III hyperlipoproteinemia: defective metabolism of an abnormal apolipoprotein E. Science (Wash. DC). 211:584-586.

16. Gregg, R.E., L.A. Zech, E.J. Schaefer, D. Stark, D. Wilson, and H.B. Brewer, Jr. 1986. Abnormal in vivo metabolism of apolipoprotein E4 in humans. J. Clin. Invest. 78:815-821.

17. Weisgraber, K.H., T.L. Innerarity, and R.W. Mahley. 1982. Abnormal lipoprotein receptor-binding activity of the human E apoprotein due to cysteine-arginine interchange at a single site. J. Biol. Chem. 257:2518-2521.

18. Wilson, J.M. 1996. Adenoviruses as gene-delivery vehicles. N. Engl. J. Med. 334:1185-1187.

19. Stevenson, S., J. Marshall-Neff, B. Teng, C. Lee, S. Roy, and A. McClelland. 1995. Phenotypic correction of hypercholesterolemia in apoE-deficient mice by adenovirus-mediated in vivo gene transfer. Arteriosclerosis Thromb. Vasc. Biol. 15:479-484.

20. Kashyap, V.S., S. Santamarina-Fojo, D.R. Brown, C.L. Parrott, D. Applebaum-Bowden, S. Meyn, G. Talley, B. Paigen, N. Maeda, and H.B. Brewer, Jr. 1995. Apolipoprotein E deficiency in mice: gene replacement and prevention of atherosclerosis using adenovirus vectors. J. Clin. Invest. 96:1612-1620.

21. Yang, Y., F.A. Nunes, K. Berencsi, E.E. Furth, E. Gonczol, and J.M. Wilson. 1994. Cellular immunity to viral antigens limits E1-deleted adenoviruses for gene therapy. Proc. Natl. Acad. Sci. USA. 91:4407-4411.

22. Yang, Y., H.C.J. Ert, and J.M. Wilson. 1994. MHC class I-restricted cytotoxic $\mathrm{T}$ lymphocytes to viral antigens destroy hepatocytes in mice infected with E1-deleted recombinant adenoviruses. Immunity. 1:433-442.

23. Engelhardt, J.F., X. Ye, B. Doranz, and J.M. Wilson. 1994. Ablation of E2A in recombinant adenoviruses improves transgene persistence and decreases inflammatory response in mouse liver. Proc. Natl. Acad. Sci. USA. 91: 6196-6200.

24. Ye, X., M. Robinson, M. Batshaw, E. Furth, I. Smith, and J.M. Wilson. 1996. Prolonged metabolic correction in adult ornithine transcarbamylase-deficient mice with adenoviral vectors. J. Biol. Chem. 271:3639-3646.

25. Sambrook, J., E.F. Fritsch, and T. Maniatus. 1989. Molecular Cloning, A Laboratory Manual. Cold Spring Harbor Laboratory Press, Cold Spring Harbor, New York.

26. Harlow, E., and D. Lane. 1988. Antibodies, A Laboratory Manual. Cold Spring Harbor Laboratory Press, New York.

27. Tsukamoto, K., T. Watanabe, T. Matsushima, M. Kinoshita, H. Kato, Y. Hashimoto, K. Kurokawa, and T. Teramoto. 1993. Determination by PCRRFLP of apo E genotype in a Japanese population. J. Lab. Clin. Med. 121:598-602.

28. Kozarsky, K.F., and J.M. Wilson. 1993. Gene therapy: adenovirus vectors. Curr. Opin. Gene. Dev. 3:499-503.

29. Menzel, H.-J., and G. Utermann. 1986. Apolipoprotein E phenotyping from serum by Western blotting. Electrophoresis. 7:492-495.

30. Gerdes, L.U., C. Gerdes, I.C. Klausen, and O. Faergeman. 1992. Generation of analytic plasma lipoprotein profiles using two prepacked superose $6 \mathrm{~B}$ columns. Clin. Chim. Acta. 205:1-9.

31. Herz, J., and R.D. Gerard. 1993. Adenovirus-mediated transfer of low density lipoprotein receptor gene acutely accelerates cholesterol clearance in normal mice. Proc. Natl. Acad. Sci. USA. 90:2812-2816.

32. Leiden, J.M. 1996. Adenovirus-mediated gene transfer as an in vivo probe of lipoprotein metabolism. Circulation. 94:2046-2051.

33. Havel, R.J. 1984. The formation of LDL: mechanism and regulation. $J$. Lipid Res. 25:1570-1576.

34. Ehnholm, C., R.W. Mahley, D.A. Chappell, K.H. Weisgraber, E. Ludwig, and J.L. Witztum. 1984. Role of apolipoprotein E in the lipolytic conversion of $\beta$-very low density lipoproteins to low density lipoproteins in type III hyperlipoproteinemia. Proc. Natl. Acad. Sci. USA. 81:5566-5570.

35. Linton, M.F., J.B. Atkinson, and S. Fazio. 1995. Prevention of atherosclerosis in apolipoprotein E-deficient mice by bone marrow transplantation. Science (Wash. DC). 267:1034-1037.

36. Vilquin, J.T., B. Guerette, I. Kinoshita, B. Roy, M. Goulet, C. Gravel, R. Roy, and J.P. Tremblay. 1995. FK506 imunosuppression to control the immune reactions triggered by first-generation adenovirus-mediated gene transfer. Hum. Gene Ther. 6:1391-1401.

37. Imler, J.L. 1995. Adenovirus vectors as recombinant viral vaccines. (Review.) Vaccine. 13:1143-1151.

38. Kozarsky, K.F., K. Jooss, M. Donahee, J.F. Strauss III, and J.M. Wilson. 1996. Effective treatment of familial hypercholesterolemia in the mouse model using adenovirus-mediated transfer of the VLDL receptor gene. Nature Genet. 13:54-62. 